\title{
Insurance as a Tool for Managing Risks in Agriculture
}

\section{Tatyana N. Kostyuchenko}

Ph.D. in Economics, Professor, Stavropol State Agrarian University

Email: kostuchenkotn@mail.ru

\section{Darya V. Sidorova}

Ph.D. in Economics, senior lecturer, Stavropol State Agrarian University

Email: sidodarya@yandex.ru

Nikolay V. Eremenko

Ph.D. in Economics, senior lecturer, Stavropol State Agrarian University

Email: eremenkomk@rambler.ru

\section{Lyudmila I. Chernikova}

Ph.D. in Economics, assistant, Stavropol State Agrarian University Email:milka87@mail.ru

\section{Doi:10.5901/mjss.2015.v6n5p220}

\section{Abstract}

\begin{abstract}
The article views the contradiction between necessity for agricultural reproduction of rational parameters for providing food security of the country and reduction of investments, primarily internal, into agrarian sphere of the economy. This condition causes the necessity for development of measures facilitating the stabilization of the sources for reproduction process in the sphere and its development. It was found that one of the most effective measures aimed at the solution of this problem is insurance. However, according to the analysis of current situation in Stavropol Krai, this tool didn't achieve a lot of success. Taking into account the found drawbacks of the existing mechanism of agricultural insurance, the authors substantiated the necessity for unification of agricultural enterprises into societies of mutual insurance support for reproduction for the purpose of minimization of risks of reduction of profit, caused by the specifics of business in this sphere. Besides, the authors offer the mechanism for their functioning and the methodology for calculation of insurance rates, differentiated according to groups of husbandries as to the type of provided reproductional process, and developed the recommendations for increase of interest of enterprises in entering the societies of mutual insurance support for reproduction.
\end{abstract}

Keywords: agriculture, reproduction process, agricultural insurance, societies of mutual insurance support for reproduction

\section{Introduction}

Agriculture is one of the most important spheres of economy of any country which provides the population with food and supplies a lot of raw materials for light, food, and processing industries. The existing type of agricultural reproduction influences significantly the state of industry: volumes of consumption by the sphere of means of industry influence the rates of development of agricultural machine building, machine building, and chemical industry. That's why one of the preconditions of successful development of agrarian sector of economy is account of its peculiarities. The most important specific feature of agriculture is use of land resources, plants, and animals, as means for production, and also of dependence of results of productive activity on uncontrolled natural climatic conditions. This circumstance causes the high riskiness of production in this sphere and, consequently, makes all the scientists of the world develop tools for risks management (Ogurtsov V.A., et al, 2008; Ibarra H., Skees J., 2007; Juyun Y., 2010; Yaghoubi J., et al, 2011; Aimin H., 2010).

At the moment, there are a lot of tools for managing risks in agriculture; however, the main tool is crop insurance which allows forming additional financial sources for implementation of reproduction activity (Zhong X., et al, 2010; Xu J., Liao P., 2014; Xing L., Lu K., 2010; Qingshui F., Xuewei Z., 2010; Yuanchang X., Jiyu J., 2010; Qing-song W.; 2010; Cole 


\section{J. B., Gibson R., 2010).}

However, modern mechanisms of agricultural insurance, especially the ones using means of state support, have their drawbacks, and, consequently, require further scientific research in this sphere (Janowicz-Lomott M., Łyskawa K., 2014; Vandeveer M. L., 2001).

That's why the main purpose of this work is development of recommendations as to creation of alternative investment reserve ensuring the maximal possible use of assets of enterprises and budgets of all levels aimed at reduction of specific risks of agrarian production, which determines their topicality.

This work is aimed at the solution of this problem, which determines its topicality.

\section{Research Methods}

The object of the research is large and medium agricultural enterprises of Stavropol Krai.

The topic of study is organizational and economic relations which determine the development of reproduction process in agriculture from the point of view of use of mechanism of insurance as an additional source for its provision.

The characterization of existing system of agricultural insurance with the help of statistical and economic methods was performed with the use of data of the Federal State Statistics Services and its territorial department in Stavropol Krai. Using the methods of correlation analysis, the pair correlation indices were calculated which allowed determining the largest dependence of the share of insured areas of the next year on the profit received by enterprises as a result of their activities.

Based on the unique methodology offered by N.I. Podturkina (Podturkina N.I., 2007) which allows compensating all agricultural risks of business structures, the authors developed the system of practical recommendations as to organization of societies of mutual insurance support for reproduction and forming mechanism of their functioning. The main task of these societies is the more effective use of budget and private assets for the purpose of reduction of agricultural risks.

Using the economic and statistical method, the authors developed the methodology for calculation of differentiated rates, which supposes the following actions: determining average crop yield for group of husbandries, dispersion, and mean-square deviation; calculating variation coefficients (variability coefficients) and sustainability of crop yield; determining coefficients of differentiation of rates; setting differentiated rates of insurance of crop yield for each enterprise; grouping enterprises using the method of statistical groups; calculating average values of differentiation coefficients of rates and of rate values.

The approbation of the offered methodology was done with the help of the data of the materials of annual reports of agricultural enterprises.

\section{Research Results}

The conducted research showed that as of now, agriculture is comprised mainly of enterprises which perform the narrow process of reproduction. This has already influenced the development of the sphere negatively and may have even worse consequences in the future. The main reason for that is instability of performance of enterprises' activity, caused primarily by variability of influence of weather conditions.

The main condition for guaranteeing the current provision of food security of the country, which consists in agricultural reproduction of rational parameters, is activization of investment process, especially by means of use of own funds. However, recently, the level of self-financing reduced, while the share of investments attracted into agrarian sector, grew. This condition emerged as a result of reduction of agricultural organizations' provision by their own working assets, and, as a consequence, necessity for bank loans. The structure of own sources of financial investment of enterprises comprises mainly of capital charges. Particularly, the current situation can be explained by fluctuations of profit of agricultural organizations, and by peculiarities of its distribution in the sphere (compensation funds, funds of private and public consumption, and reserve fund are created at first, with accumulation fund coming next).

It should be noted that instability of the value of enterprises' profit, including the profit given for investments, is caused by peculiarities of reproduction process in agriculture. Its specific consists in the fact that the productive process in the sphere is related to use of plants and animals, as means of production, the development of which obeys the natural laws and depends mainly on uncontrolled natural and climatic conditions. Optimal weather conditions are periodically changed by unpredicted drought, frost, hail, precipitation, and other mainly factors. Besides, agricultural plants and animals often suffer from various diseases and pests. As a result, income, and, correspondingly, profit of enterprises significantly differ from the planned level, which eventually influences the reproduction process in the sphere negatively. 
The dependence of profit, which is used for enterprise's development, on the income, received by agricultural enterprises, may be reduced with the help of activization of the use of insurance mechanism, which ensures reserving of investment funds. It should be noted that insurance is one of the most convenient methods for state regulation of development of agriculture under conditions of Russia's joining WTO, as it is included into "green" basket of state support measures.

The meaning of insurance from the point of view of providing investment reserve in agriculture consists in the fact that for the purpose of minimization of possible losses from unfavorable influence of weather and other factors of production, which are not well-controlled by manufacturers, and of preserving income in the sphere, agricultural enterprises (insuring parties) obtain from insuring organizations (insurers) the guarantee for recovery of possible losses for a certain fee (insurance premium, up to 2012 - insurance payment).

According to Clause 1, Article 32.9 of the Law of the Russian Federation dated 27.11.1992 No. 4015-1 "Concerning the Organization of Insurance in the Russian Federation" and Article 7 of the Federal Law dated 25.07.2011 No. 260-FZ "Concerning the State Support for Agricultural Insurance and Introduction of Amendments to the Federal Law "On Agricultural Development", agricultural insurance includes the following types:

1. Insurance of agricultural plants crop;

2. Insurance of perennial plantings;

3. Insurance of agricultural animals.

The first type of insurance is the most popular one in Stavropol Krai. Primarily, it can be explained by the fact the agricultural organizations of the region which specializes on the production of corn suffer regular losses due to unfavorable natural phenomena (up to $30 \%$ in certain years). Besides, insurance of agricultural plants crop has the greatest support from the state.

The meaning of this type of insurance consists in the fact that agricultural organizations conclude contracts of voluntary insurance of future crop with insurance organizations. The following crops can be insured: cereal crops, grain legumes, oil-bearing, industrial, forage, gourds, potato, vegetables crops; vineyards; horticultural, currant, and nut bearing plantings; hop and tea plantations. The list of agricultural risks is comprehensive and allows the enterprises of agrarian sphere to compensate their losses in case of any unpredicted situation of natural character. Insuring party can insure the agricultural plants crop against the possibility of total loss of crop and (or) its partial loss.

However, it should be noted, that the existing system of agricultural insurance has certain drawbacks:

- strict deadlines for payment of insurance premia, as required by the law. The payment of $50 \%$ of the fee should be made during the period of preparation and conduct of sowing works, when enterprises can experience the lack of money;

- drawbacks of existing legal basis that regulates the system of agricultural insurance with state support, as a result of which enterprises do not receive full subsidies for payment of insurance premia;

- high profitability of insurance organizations (bonus for compensation of costs for conduct of insurance operations constitutes $9-40 \%$ of paid insurance premia);

- fixed insurance rates which do not take into account different levels of agricultural risks in certain regions and organizations of one region;

- lack of special departments of insurance expertise, which calculate the volumes of insurance premia and payments of insurance indemnity, check the originality of data, stated in insurance agreements, and control the use of funds and reserves of insurance companies.

On the territory of Stavropol Krai, the number of agricultural organizations which insured their crops reduced from 151 to 107 during 2004-2010 (almost by 30\%), but the following year it grew by 1.5 times and reached 161 enterprises. The area of insured crops didn't exceed $20 \%$ of all crop area in 2004-2006. During the following three years, this indicator grew and reached $32 \%$. In 2010, the share of insured crop area of agricultural plants in the total crop area reduced to the level of 2004, but 2011 demonstrated the positive tendency for increase of area of insured crops (Table 1). Winter cereals crops comprise $75-95 \%$ of the structure of insured crop areas.

Table 1. Share of insured crop areas in total crop areas of agricultural enterprises of Stavropol Krai, \%

\begin{tabular}{|l|c|c|c|c|c|c|c|c|}
\hline Indicator & 2004 & 2005 & 2006 & 2007 & 2008 & 2009 & 2010 & 2011 \\
\hline Crop areas, thousand hectares & $2,249.3$ & $2,217.9$ & $2,275.4$ & $2,347.0$ & $2,366.7$ & $2,380.2$ & $2,320.7$ & $2,327.8$ \\
\hline Insured crop areas, thousand hectares & 463.4 & 439.1 & 405.0 & 584.4 & 719.5 & 766.4 & 478.1 & 542.4 \\
\hline Share of insured crop areas in total crop areas, \% & 20.6 & 19.8 & 17.8 & 24.9 & 30.4 & 32.2 & 20.6 & 23.3 \\
\hline
\end{tabular}


It should be noted that the lowest share of insured crop areas was observed in Neftekumsk, Novoaleksandrovsk, Stepnovsk, Kransogrvardeysk, and Kirovsk regions of the Krai, which are located in differed natural and climatic zones and, correspondingly, significantly differ as to the level of riskiness of production of plant products. The pair correlation coefficients were calculated in order to study the reasons of the current situation. The dependent variable was the share of insured areas of the following year, while the crop yield of corn plants, average price, and enterprises' profit were viewed as independent variables (Table 2).

Analysis of received results showed that the largest influence on the change of the share of crop areas, which will be insured the following year, in the total crop areas is performed by the volume of profit, received by enterprises as a result of activities. Corn price and crop yield influence this indicator a bit less. Thus, the direct influence in the decision making as to crop insurance and, correspondingly, as to the share of insured crop areas is done by agricultural organizations' sufficiency or insufficiency of money for payment of insurance premia during the period of field works (Kostuchenko T.N., Sidorova D.V., 2013).

Table 2. Calculation of pair coefficients of correlation

\begin{tabular}{|c|c|c|c|c|}
\hline Year & Share of insured areas of the following year & Crop yield of corn plants, center/hectare & Corn price, RUB/ton & Profit, RUB million \\
\hline 2000 & 9.5 & 22.4 & 2,125 & $1,838.6$ \\
\hline 2001 & 11.3 & 26.8 & 2,256 & $2,090.1$ \\
\hline 2002 & 23.9 & 31 & 1,796 & $1,772.8$ \\
\hline 2003 & 20.6 & 21.8 & 2,592 & $2,217.9$ \\
\hline 2004 & 19.8 & 32.0 & 3443 & $3,535.1$ \\
\hline 2005 & 17,8 & 34,1 & 2364 & 2169,2 \\
\hline 2006 & 24,9 & 31.3 & 3,064 & $4,022.7$ \\
\hline 2007 & 30.4 & 32.3 & 5,067 & $7,734.0$ \\
\hline 2008 & 32.2 & 37.3 & 5,242 & $6,754.1$ \\
\hline 2009 & 20.6 & 31.9 & 4,157 & $3,512.9$ \\
\hline 2010 & 23.3 & 32.1 & 3,935 & $4,766.1$ \\
\hline 2011 & 27.2 & 38.7 & 5,272 & $5,814.1$ \\
\hline & Pair correlation & 0.56 & 0.65 & 0.72 \\
\hline
\end{tabular}

During 2004-2011, the size of insurance premium, paid for insuring the crop with state support, increased by 6.2 times. Agricultural organizations pair 56-64\% of the premia in 2004- 2006, 2009, and 2011. In 2007-2008 and 2010, this indicator constituted $50 \%$ (Figure 1).

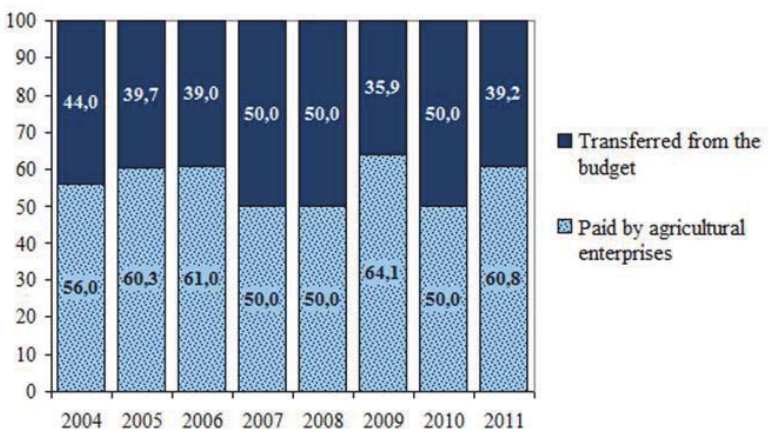

Figure 1. Structure of insurance premia for insuring crop of agricultural plants with state support in Stavropol Krai, \%

Besides, it should be noted that during the whole viewed period (except for 2006), the size of paid insurance premia significantly exceeded the value of insurance indemnities, paid to husbandries (Figure 2). In 2004-2005 and 2009-2011, up to $36 \%$ of payments received by the insurance companies were used for these purposes, and in 2008, due to the economic crisis, the indemnities were not paid at all. 


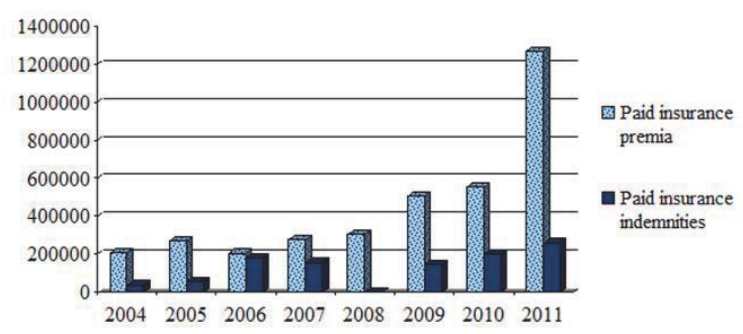

Figure 2. Dynamics of values of paid insurance premia and insurance indemnities in Stavropol Krai, RUB thousand.

The above mentioned is caused by the imperfection of the mechanism of agricultural insurance with state support. Thus, for example, insurance payout to enterprises is performed only if the volume of lost crops comprises no less than 30\%; as a result, most of money, paid as insurance premia, is left in insurance organizations as a profit. This leads to the fact that attractiveness of crop insurance reduces, as insurance parties' mistrust to insurers grows.

In order to increase the role of household insurance, as an investment reserve for reproduction process at enterprises of agrarian sphere of Stavropol Krai and to manage the risks in the sphere, it is necessary to develop alternative types of insurance. In this situation, the most optimal is uniting the agricultural enterprises into societies of mutual insurance support for reproduction. The mechanism of organization of their business is based on the methodology offered by N.I. Podturkina (Podturkina N.I., 2007). The organization of activities of recommended societies is presented in Figure 3.

Societies of mutual insurance support for reproduction should be created in the form of non-commercial organizations which function on the co-op; at that, their activity is regulated by the Civil Code of the RF, the Law of the RF "Concerning the Organization of Insurance in the Russian Federation", the Federal Law of the RF "Concerning Agricultural Co-Operation", Federal Law of the RF "Concerning Mutual Insurance", and Federal Law of the RF "Concerning Non-Commercial Organizations". Stimulation the creation and development of societies for mutual insurance support for reproduction should be performed by means of state support in the form of additional subsidies for the payment of insurance premia to their members.

It should be nored that implementation of insurance protection requires the enterprises-members of offered societies to unite their own funds, which already passed taxation, without aiming at gaining profit from their activity. Consequently, all incomes and expenses of the soeieties are incomes and expenses of non-commercial operations, i.e., societies of mutual insutance support for reproduction do not produce profit from insuring enterprises and do not distribute it between their members. As is well-known, incomes and expenses of non-commercial operations are not subject to tax.

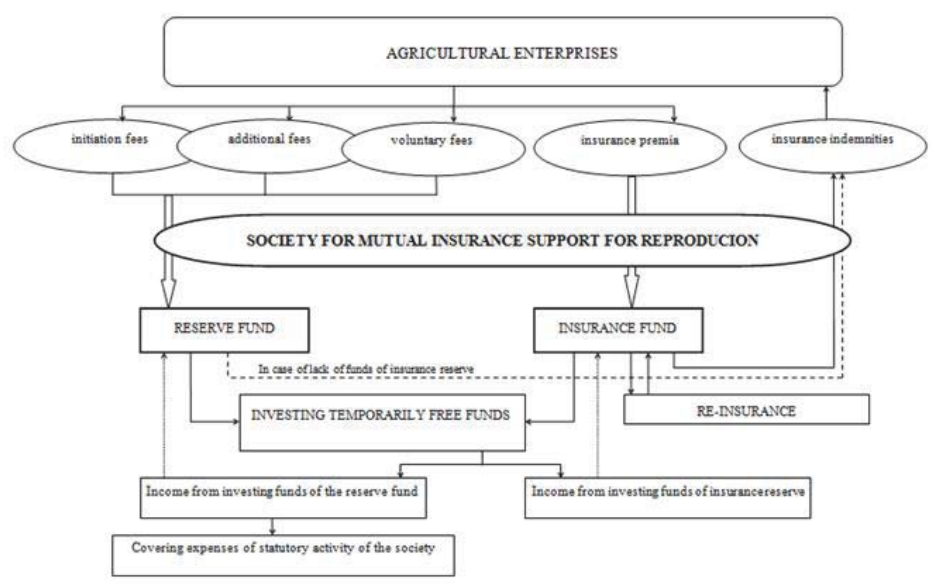

Figure 3. Mechanism of organization of activity of a society of mutual insurance support for reproduction. 
General meeting of the members of the society of mutual insurance support for reproduction should elect or involve a third party for the special service of insurance expertise. The main tasks if this service is calculation of size of insurance premia and insurance indemnities, creation of reserves, investment activity for the purpose of reducing the size of insurance premia in the future, short-term crediting of the society's members by means of temporarily free funds (especially in yielding years, when there is no necessity for paying indemnities).

One of the main conditions for providing the sustainability for insurance operations and increase of guarantees for insurance indemnities in societies of mutual insurance support for reproduction is obligatory use of the mechanism of reinsurance. Its implementation under the most profitable conditions requires their uniting into regional and transregional unions of societies for mutual support for reproduction. Reasonability of formation of mentioned unions is predetermined by substantial differences in natural and climatic conditions, which provide direct influence on the yield of agricultural crops - in separate areas of one region and between different subjects of the federation. As a result, the societies for mutual insurance support for reproduction of some areas and regions have the excess of insurance premia, while others need assets for insurance indemnities. In other periods they switch places. Redistribution of assets under the most profitable conditions is possible only with creation of regional and transregional unions of societies for mutual insurance support for reproduction. Their appearance should be encouraged with the help of targeted loans. Thus, advantages of societies for mutual insurance support for reproduction are doubtless:

1) agricultural enterprises are at the same time insuring parties and insurers, which allows them to set their own rules and conditions for insurance; as societies for mutual insurance support for reproduction emerge as noncommercial organizations, i.e., do not strive for profit, the cost of this type of insurance is lower than with commercial organizations;

2) funds and reserves of the societies, including assets of state support, remain in the insuring party's disposal and are not transferred to insurers, as is done with commercial insurance;

3) cooperation and mutual control of members of societies for mutual insurance support for reproduction allow receiving the truest information as to compliance with conditions of insurance, occurrence of the insured event, accuracy of calculations of insurance premia, and justification of insurance payouts.

Creation of societies for mutual insurance support for reproduction will also give the possibility to solve the problem of period of payment of the part of insurance premium from the budget. At present, $50 \%$ of insurance premium is paid by agricultural enterprises, and the another $50 \%$ is transferred in the form of subsidies to the accounts of insurance organizations. At that, there are situations when with occurrence of insured event the agricultural organizations do not receive full payouts. This situation is caused by the fact that sometimes budget assets for paying another half of the payout are not available in time, and insurers refuse to accept them in order not to pay the whole sum of indemnity. On the other hand, most of enterprises of agrarian sphere are in a very difficult situation, so they do not have the possibility to pay the insurance premia themselves and receive subsidies on their accounts. In societies for mutual insurance support for reproduction there will be no such problem, as, being simultaneously insurance party and insurer, the members of the society are interested in receiving indemnities in full, and, consequently, it will be possible to set flexible period of subsidies payment.

It should be noted that at present, rates for insuring the agricultural crop are differentiated for the subjects of the federation and for certain types of agricultural crops. However, as is known, weather conditions differ not only in different subjects of the federation and in natural and climatic areas of the region but also within one administrative region. Besides, their influence on the results of productive activities also depends on the level of use of new technologies in husbandries which provide their sustainability. Thus, risk of occurrence of unfavorable weather conditions and, consequently, risk of loss or damage of crop is different for each enterprise. Thus, it is advisable to set insurance rates for societies for mutual insurance support for reproduction which are differentiated not only for subjects of the federation and different types of agricultural plants but for groups of husbandries. Methodology for calculation of differentiated rates allows zoning region's enterprises as to the level of riskiness of their activities and is based on the analysis of sustainability of yield of certain agricultural plants and its deviation from average value in view of enterprises. The offered methodology was tested by the example of yield of cereal crops of large and medium agricultural organizations of the second natural and economic zone of Stavropol Krai.

Methodology for calculation of differentiated rates can be represented in the form of sequence of the following actions:

1. Based on the actual data on yield at each enterprise for the last 12 years, it is necessary to determine their average yield, dispersion (1), and then mean-square deviation (2):

$\delta^{2}=\frac{\sum(\mathrm{x}-\bar{x})^{2} \mathrm{n}}{\sum \mathrm{n}}$, 
where $x$ - factor value,

$\mathrm{n}$ - factor repetition frequency

$\delta=\sqrt{\delta^{2}}$;

2. The next stage includes calculation of coefficients of variation (variability) of yield as a ratio of mean-square deviation to average yield;

3. Coefficients of sustainability are determined as difference between 1 and coefficient of variation;

4. Based on the coefficients of sustainability, coefficients of differentiation of rates are determined (average as to the side value of the coefficient of sustainability is considered to equal 1);

5. Using the coefficients of differentiation, the differentiated rates of insurance of cereal crop yield for each enterprise are calculated. The offered rates are calculated using the basic rate, which constitutes $6.3 \%$ of amount of insurance with cereal crop insurance in Stavropol Krai. Differentiated rates which are used for insurance with the deductible franchise of $5-40 \%$, offered by the "Plan for agricultural insurance", are calculated similarly;

6. In view of a large number of agricultural organizations and differences in average yield of cereal crops and level of its sustainability, the enterprises, with the help of statistical grouping method, are divided into 4 groups;

7. For the allocated groups of enterprises, the average values of coefficients of differentiation of rates are determined, which are then used for calculation of the size of rates (Table 3).

Table 3. The offered differentiated rates for insurance of cereal crop as to grouping of enterprises according to the level of their yield sustainability

\begin{tabular}{|c|c|c|c|c|}
\hline No. of group & $\begin{array}{c}\text { Average yield, } \\
\text { center/hectare }\end{array}$ & $\begin{array}{c}\text { Sustainability } \\
\text { coefficient }\end{array}$ & $\begin{array}{c}\text { Average coefficient of } \\
\text { differentiation }\end{array}$ & $\begin{array}{c}\text { Offered differentiated rate } \\
\text { (basic rate 6.3\%) }\end{array}$ \\
\hline 1 & 31.7 & $\leq 0.800$ & 1.206 & 7.60 \\
\hline 2 & 29.3 & $0.801-0.856$ & 1.083 & 6.82 \\
\hline 3 & 30.3 & $0.857-0.911$ & 1.015 & 6.39 \\
\hline 4 & 32.8 & $\geq 0.912$ & 0.956 & 6.02 \\
\hline
\end{tabular}

As a result of use of rates that are differentiated as to husbandries groups according to the level of yield sustainability in societies for mutual insurance support for reproduction, it is possible to reduce the rate almost by $0.3 \%$ for organization of the most sustainable $4^{\text {th }}$ group of enterprises (their share in the studied aggregate constitutes $15 \%$ ). Such a small reduction of insurance rates may be explained by the fact that the studied enterprises are situated in the second agricultural zone of Stavropol Krai. This zone is dry, which influences significantly the rises and falls of cereal crop yield in agricultural organizations. In the future, under the condition of the further growth of sustainability of yield, the annual reduction of insurance rates for husbandries of this group is possible. In order to increase these enterprises' interest in joining societies for mutual insurance support for reproduction, it is possible to grand them short-term loans for production needs, the interest rate of which will constitute $1 / 4$ of the bank interest rate, by means of temporarily free assets of the society.

The third group of husbandries includes enterprises (around the half of the husbandries of the viewed area), the crop yield sustainability of which is somewhat lower than the average value in Stavropol Krai. As a result, the rate, offered by societies for mutual insurance support for reproduction for this group of husbandries, exceeds the basic rate for insuring cereal crop in the region by $0.09 \%$. In order to attract these agricultural organizations into societies for mutual insurance support for reproduction, it is recommended to grant them short-term loans on special terms, as compared to bank terms ( $1 / 3$ of the bank interest rate).

Sustainability of cereal crops yield in agricultural organizations which comprise the $2^{\text {nd }}$ group, are lower than the average as to the side by 0.012 items. That's why for insuring the husbandries of the mentioned group in societies for mutual insurance support for reproduction the offered rate constitutes $6.82 \%$, which is by $0.52 \%$ higher than the basic rate. It is possible to increase the interest of these enterprises in joining societies for mutual insurance support for reproduction with the help of loans for production needs with recommended interest rate of $2 / 3$ of the bank interest rate.

The first group of the least sustainability of yield is comprised by 7 enterprises, at which the insurance events occur more often than at other organizations. As a result, the insurance rate, offered for these husbandries, is the maximal one $-7.6 \%$ of the insurance sum. However, joining societies for mutual insurance support for reproduction has advantages even for these enterprises, as receiving state support and insurance indemnities in case of insurance event occurrence is guaranteed. 
The offered methodology for differentiation of rates is very simple in use, as with the modern level of development of informational technologies for processing of statistical information, there should not be any difficulties while working with it.

The use of the offered rates, differentiated as to husbandries groups depending on the level of crop yield sustainability, will allow increasing the attractiveness of societies for mutual insurance support for reproduction for enterprises of agrarian sphere. Besides, in the future, the activity of the societies may cover the insurance for perennial plantings and agricultural animals, insurance for other property (industrial buildings, machines, equipment, and transport) of enterprises, and insurance for income of agricultural organizations in case of huge reduction of prices for the produced goods.

Thus, creation of societies for mutual insurance support for reproduction will allow increasing the prestige of insurance in agrarian sector of economy, and agricultural enterprises will acquire an additional source of investments for achieving the rational parameters of reproduction process.

\section{Conclusions}

Modern state and tendencies of the development of agriculture do not correspond to the requirements of the necessity for provision of reproduction process with rational parameters. This sphere is dominated by narrow type of reproduction, as financial results of large and medium agricultural enterprises do not allow preserving the accumulated resource potential. A significant influence on this situation, together with inflation and existing disparity of prices for agricultural products and material \& technical resources, necessary for production in the sphere, is done by dependence of the results of enterprises' activities on the influence of weather conditions. In order to reduce the dependence of profit size, used for development of production, in the size of income of agricultural enterprises, the activization of the use of insurance mechanism is required, as well as more effective use of budget and private assets, aimed at reduction of specific sectorial risks. In order to solve this task, it is recommended to organize the societies for mutual insurance support for reproduction on cooperative basis. In order to increase the interest of agricultural enterprises which are referred to simple and expanded reproduction in these societies, it is possible to set insurance rates which are differentiated as to groups of husbandries sustainability according to the developed methodology and grant them short-term loans for production needs by means of temporarily free assets, under special terms, as compared to the bank terms.

\section{References}

Aimin H. (2010). Uncertainty, Risk Aversion and Risk Management in Agriculture. Agriculture and Agricultural Science Procedia, 1, 152156.

Cole J. B., Gibson R. (2010). Analysis and Feasibility of Crop Revenue Insurance in China. Agriculture and Agricultural Science Procedia, 1, 136-145.

Ibarra H., Skees J. (2007). Innovation in risk transfer for natural hazards impacting agriculture. Environmental Hazards, 7, 1, 62-69.

Janowicz-Lomott M., Łyskawa K. (2014). The New Instruments of Risk Management in Agriculture in the European Union. Procedia Economics and Finance, 9, 321-330.

Juyun Y. (2010). The Optimization Path and the Integration Mechanism of Agricultural Insurance in the Charge of Government. Agriculture and Agricultural Science Procedia, 1, 258-261.

Kostyuchenko T.N., Sidorova D.V. (2013). Peculiarities of reproduction process in agriculture: monograph. Stavropol, 156.

Ogurtsov V.A., Van Asseldonk M.P.A.M., Huirne R.B.M. (2008). Assessing and modelling catastrophic risk perceptions and attitudes in agriculture: a review. NJAS - Wageningen Journal of Life Sciences, 56, 1-2, 39-58.

Podturkina N.I. (2007). Formation of the risk management system in agrarian production (by the example of crop research): abstract by Ph.D. in Economics. Rostov-on-Don, 26.

Qingshui F., Xuewei Z. (2010). Development Strategies on Agricultural Insurance under the Building of New Countryside. Agriculture and Agricultural Science Procedia, 1, 13-23.

Qing-song W. (2010). The Farmers Behavior in Agricultural Insurance under the Von-Neuman-Morgenstern Utility Model. Agriculture and Agricultural Science Procedia, 1, 226-229.

Vandeveer M. L. (2001). Demand for area crop insurance among litchi producers in northern Vietnam. Agricultural Economics, 26, 2, 173-184.

Xing L., Lu K. (2010). The Importance of Public-Private Partnerships in Agricultural Insurance in China: based on Analysis for Beijing. Agriculture and Agricultural Science Procedia, 1, 241-250.

Xu J., Liao P. (2014). Crop Insurance, Premium Subsidy and Agricultural Output. Journal of Integrative Agriculture, 13, 11, $2537-2545$.

Yaghoubi J., Shokri M. E., Gholiniy J. M. (2011). Assessing agricultural insurance agents attitude towards e-learning application in teaching them. Procedia-Social and Behavioral Sciences, 15, 2923-2926.

Yuanchang X., Jiyu J. (2010). The optimal boundary of political subsidies for agricultural insurance in welfare economic prospect. 
Agriculture and Agricultural Science Procedia, 1, 163-169.

Zhong X., Qiao Y., Lin W., Li M., Fang W. (2010). On the Pilot Agriculture Insurance Program in Zhejiang Province. Agriculture and Agricultural Science Procedia, 1, 146-151. 